\title{
Facebook as an e-Portfolio Platform in the EFL/ESL Writing Classrooms
}

\author{
Jessie S. Barrot (Manila/ Philippines)
}

\section{Introduction}

Information and communication technology (ICT) has recently been changing the landscape of communication, processing of information and even the field of education. Although ICT was not originally intended for educational purposes, it continues to gain popularity as a supplementary resource to support learning (Traore \& Kyei-Blankson 2011) because of the many benefits it offers to both teachers and learners. It promotes collaboration (Khan et al. 2012, Ndebele 2017), provides an engaging and motivating environment (Chun \& Plass 1997, Hsu 2011, Kern \& Warschauer 2000), develops $21^{\text {st }}$ century skills (Barrot 2015b, Voogt et al. 2013) and enhances language proficiency (Kessler \& Hubbard 2017, Tsai \& Jenks 2009, Wang 2004).

One important ICT innovation is social networking sites (SNS). SNS are virtual communities that allow users to interact and connect with other people, build social relationships, share information and create personal profiles (Makri \& Schlegelmilch 2017, Nadkarni \& Hofmann 2012). The most popular SNS include Flickr, Instagram, LinkedIn, MySpace, Pinterest, Snapchat, Twitter, Tumblr and Facebook. With their increasing popularity, their influence has spread to language classrooms. In fact, many language educators and scholars (e.g. Barrot 2016, Jong et al. 2014, Lomicka \& Lord 2016, Mazman \& Usluel 2010, Roblyer et al. 2010, Sánchez et al. 2014) attest to their ability to facilitate language learning. 
Among the many available SNS, Facebook is considered to be the most popular and influential among students (Shepherd 2015). However, a few scholars have raised concerns regarding its use for teaching purposes. For instance, Hew (2011), Madge et al. (2009) and Sarapin \& Morris (2015) reported that Facebook could be inefficient as a teaching and learning tool. Meanwhile, Prescott et al. (2013) argued that Facebook may be effective in informal learning but not in a formal educational context. Some teachers, too, are reluctant about using Facebook for classroom purposes for various reasons (Ajjan \& Hartshorne 2008, Manca \& Ranieri 2016, Roblyer et al. 2010). Three of these reasons may be their own lack of skills in manipulating technology, the lack of technology for classroom teaching, especially in the developing countries and privacy issues such as the invasion of students' personal space. Despite the challenges to using Facebook as an educational tool, however, a consensus remains that it can be a powerful tool for computer-assisted language learning because of its flexibility, usefulness and cost-efficiency (Akbari et al. 2015, Barrot 2016, Jong et al. 2014, Kabilan et al. 2010, Mazman \& Usluel 2010, Roblyer et al. 2010, Sánchez et al. 2014).

While there have been many instances where Facebook has been used for language teaching and learning purposes, very few have attempted to use it as an e-portfolio platform. Hence, this chapter focuses on how Facebook can be used as an e-portfolio platform in EFL/ESL writing classrooms. I have divided the discussion into five sections. The first three sections talk about portfolio assessment in general, Facebook in an educational context and Facebook in foreign/second language teaching. The next section zeroes in on the preparation and implementation of a Facebook-based e-portfolio. The chapter concludes with some challenges and recommendations for future implementation.

\section{Portfolio assessment}

The advent of alternative assessment in writing has pushed educators and scholars to think of ways to authentically, practically, reliably and validly capture students' performance. One of these alternative forms of assessment is portfolio assessment, which allows students to collect, store, manage and reflect on their written work and on how they progress over time (Hamp-Lyons \& Condon 2000, Weigle 2007). Among the many advantages of using portfolio assessment are that it: (1) facilitates seamless integration between assessment, teaching and learning; (2) allows students to showcase their mastery of the writing process; (3) facilitates student learning; (4) empowers both students and teachers, (5) improves the quality of assessment; (6) facilitates self-regulated learning; (7) increases student motivation; (8) promotes metacognition; (9) increases rhetorical, cultural and audience awareness; (10) allows teachers to assess students' writing performance holistically rather than in isolation (Barrot 2015a, Brown \& Hudson 1998, Byon 2007, Cheng 2009, Lam 2014, Lam 2017, Lee 2017, Morris 2003, Russell \& Butcher 1999, Zusho \& Edwards 2011). 
Portfolio assessment may be classified in terms of purpose and delivery. In term of purpose, a portfolio can be a display, developmental, or outcome-based portfolio. A display portfolio allows students to showcase their best-written work among the many texts that they have produced during the course of writing sessions. A developmental portfolio (also known as a working portfolio) is a type of portfolio that allows students to show their drafts along with the final paper. Finally, there is outcome-based portfolio (or assessment portfolio) that showcases the written work which fulfills the requirements set by the curriculum.

In terms of delivery, portfolio assessment may be delivered in paper (paperbased portfolio) or electronic form (electronic portfolio). A paper-based portfolio is the traditional form of the portfolio, which is static and uses paper to showcase students' work (Challis 2005). Although easy to prepare, it may not be appealing to the writers and the readers themselves. This paper-based portfolio may also be relatively costly to prepare and restricted to a limited audience. These limitations have pushed educators to find a different yet equally effective mode of portfolio presentation. The result is the electronic portfolio or e-portfolio. Unlike its predecessor, in e-portfolios written work is collected, stored and managed electronically. Traditional e-portfolios use an offline mode such as compact discs (CDs) while the contemporary ones use Web 2.0 technologies such as SNS, emails and websites. Lorenzo and Ittelson (2005: 3) define the latter as a "personalized, web-based collections of work, responses to work, and reflections that are used to demonstrate key skills and accomplishments for a variety of contexts and time periods". Some of the advantages of using a Web 2.0 e-portfolio are its wider readership, real-time publication of work, flexibility, interactive features, accessibility and appeal to $21^{\text {st }}$ century learners (Barrot 2016, Baturay \& Daloglu 2010, Cheng 2009, Chye et al. 2013, Kabilan \& Khan 2012, Meyer et al. 2010, Waters 2009).

\section{Facebook in educational contexts}

Facebook is an online social media and networking site that allows users to stay connected with family and friends, discover the events happening around them and express ideas on topics that matter to them. To date, it has 2.07 billion monthly active users from various backgrounds, cultures and age groups. Its main goal is to empower people in building communities and bringing the world closer together (Facebook 2018). Its most common user age group is young adults (Shepherd 2015: 86).

With the increasing popularity of Facebook among young adults, a number of educators and scholars have embarked on using Facebook for educational purposes, especially in higher education (see Aydin 2012, Blankenship 2011, Hew 2011, Mazman \& Usluel 2010, Manca \& Ranieri 2013, Manca \& Ranieri 2016, O’Bannon et al. 2013, Prescott 2014, Roblyer et al. 2010, Sánchez et al. 2014, Yang et al. 2011). Its influence even extends to other fields, such as business (Ramirez et al. 
2009), culture (Mills 2011), humanities (Robelia et al. 2011, Shin 2010), literacy development (Greenhow 2009) and sciences (Schroeder \& Greenbowe 2009).

The use of Facebook in education may either be in a formal or informal context. A formal context is structured and controlled by the teacher and/or the institution (e.g., classroom and curricular contexts in basic, tertiary, or post-graduate levels) while an informal context is unstructured and not controlled by the teacher and/or the institution (e.g., non-classroom and non-curricular contexts) (Werquin 2010). However, this distinction has been questioned by various scholars, who argue that almost all, if not all, learning contexts are a combination of both (Greenhow \& Lewin 2016, Malcolm et al. 2003).

As an education tool, Facebook offers several useful features such as Groups, Pages, About, Make Post, Comment, Messenger, QR Codes, Poll and Events. For instance, the Comment feature can be used when providing feedback on students' output while the Make Post tab can be used to update students on class activities and requirements. When setting deadlines, teachers may use the Events section. In the case of controlling visibility and sharing of information, the Groups feature may be used. There is also the Messenger, which allows students to interact with one another in real time. All of these features allow peer and teacher feedback and promote collaboration, interaction and information sharing among learners (Selwyn 2009, Tapscott \& Williams 2010). These innovative features of Facebook have been found to enhance self-esteem (Bowers-Campbell 2008, Ellison et al. 2007), motivate students (Siegle 2011), reduce anxiety (West et al. 2009), facilitate differentiation (Hew 2011) and mentoring (Schwartz 2009) and enhance interaction between students and teachers (Lampe et al. 2008). Nonetheless, there are reported disadvantages in using Facebook for academic purposes. Some studies reported that it causes anxiety among students (Shih 2011, Wichadee 2013), is logistically demanding (Barrot 2016, Aydin 2014) and distracts students from doing their assignment (Shih 2011).

\section{Using Facebook in foreign/second language teaching}

Even educators and scholars in the field of language teaching have started to become interested in using Facebook for pedagogical purpose (e.g. Akbari et al. 2015, Barrot 2016, Dizon 2016, Kabilan et al. 2010, Özdemir 2017, Shepherd 2015, Shih 2011, Shih 2013, Wichadee 2013, Yen et al. 2015). All of these studies have found that Facebook, in general, facilitates language teaching and learning.

Of these studies, Barrot (2016), Dizon (2016), Shepherd (2015), Shih (2011) and Wichadee (2013) focused on the impact of Facebook on students' writing. For instance, Shih (2011) investigated how the integration of peer assessment and Facebook would affect students' writing performance. Using both quantitative and qualitative analysis, she found that this type of blended approach improved students' writing skills, knowledge and motivation in writing because of Face- 
book's flexibility and accessibility. She further reported that the meaningful interaction among students also facilitated their improvement. The same findings were obtained by Wichadee (2013), who reported that Facebook-based peer assessment helped improve students' revisions. Findings also revealed students' positive attitude toward the use of Facebook, essentially because Facebook is interactive, provides a more engaging learning environment and allows them to interact meaningfully. Another study that investigated the integration of Facebook into a writing class was that of Shepherd (2015), who examined students' composition practices on Facebook. With 474 first-year composition students as participants, he found a relevant connection between students' writing practices on Facebook and their writing classrooms. Although they initially hesitated to use Facebook for writing purposes, they were able to overcome this hesitation. The findings even revealed that students became more aware of their rhetorical situation and space, which would make them more effective writers.

Dizon (2016) examined the effects of Facebook-based writing on L2 learners' lexical richness, writing fluency and grammatical accuracy. After the 12-week treatment, he found that students who used Facebook as a platform for writing made more progress in writing fluency compared to students from the control group. However, non-improvement was reported on students' grammatical accuracy and lexical richness due to lack of built-in marking features in Facebook.

Among all the studies conducted, only Barrot (2016) has used Facebook as an e-portfolio. In this study, students used Facebook as an e-portfolio platform in their academic writing classes. Using a self-report questionnaire, he found that students had a positive attitude toward a Facebook-based e-portfolio and that it positively impacted on their writing practices. Students reported that this type of e-portfolio allowed them to monitor their progress, recognize the gaps in their skills and reflect on their performance. However, some challenges in using Facebook-based e-portfolio were reported, such as Internet connections, typing and compilation, format and readability and anxiety issues (i.e., enabling anxiety).

\section{Facebook as an e-portfolio platform}

The teaching of writing in the Philippines at all levels has shifted from a product to a process approach. And with the advent of technology, writing pedagogy also integrates the principles of $21^{\text {st }}$ century learning in order to help learners survive in today's highly globalized economy. This integration requires writing teachers to use technology in the teaching-learning process. One way to realize this is through the use of an e-portfolio. However, not many schools and universities adopt this practice due to limited infrastructure and poor Internet connections in the Philippines, especially in the rural areas. Despite these challenges, a great majority of Filipinos (including teachers and students) are familiar with and active users of Facebook (Camus 2018). 


\subsection{Preparatory stage}

The first step in implementing a Facebook-based e-portfolio is to set up a class Facebook account in which the teacher will be the administrator. This account may be used for one writing class or multiple classes. As for the students, they need to use their existing personal Facebook accounts for the posting of their work via the class account. In this way, the students will have a ready-made audience for their work. If they do not have a Facebook account yet, they need to create one and add some friends prior to publication of their work. To reduce students' anxiety, they can limit the visibility of their work to a 'friendly' audience through the closed group feature of Facebook.

The next step is to incorporate the e-portfolio guidelines into the syllabus for the students' reference. These guidelines are explained to them during the first week of classes. The coverage of the orientation includes the purpose, nature and format of the e-portfolio as well as the procedure for preparing it. Then, the teacher distributes and explains a sample e-portfolio. To facilitate the grouping of students per section, they need to be instructed to add the class Facebook account using their personal Facebook account. Then, the teacher groups each class section using the Group List feature.

Note that the type of e-portfolio that students need to prepare is a showcase portfolio. A showcase portfolio is designed to display students' best output to highlight their success over a period of time. Some advantages of using showcase e-portfolio are as follows: (1) it allows students to reflect on their best work, (2) it allows students to make the best impression of themselves and (3) it highlights their personality.

\subsection{Writing sessions}

One of the teaching approaches to writing that systematically integrates Facebookbased e-portfolio is the sociocognitive-transformative approach (Barrot 2014, 2015a, 2015b), which has been empirically tested and shown to improve students' writing performance (Barrot 2018). This approach follows eight stages of writing, namely preparation, modeling, planning, collaborative writing, individual writing, revising, editing and publishing.

During the preparation stage, the teacher sets the context for writing and activates the students' schemas. For their part, the students specify their topic, general and specific purpose, target audience and level of formality of writing for a particular text. Since topic interest and familiarity influence the writing performance, students are free to choose any topics as long as they are socially relevant.

The next stage is modeling, which involves the analysis of structure and rhetorical features as well as the language used in the sample texts. At this stage, students are exposed to at least two model texts. Each text is processed using guiding questions that focus on structure, target audience and purpose of each text. 
The planning stage allows students to brainstorm, conduct preliminary research about the selected topic and prepare an outline in groups. Brainstorming is performed through listing, free writing, mapping, or clustering. Then, the students use the ideas they have generated for preliminary research. Afterwards, they begin preparing their outline, which will be the basis for their drafting. Note that students cannot proceed to the drafting stage unless their outlines are approved by their teacher. The teacher's approval is important to ensure the quality of students' output.

After the planning stage comes the collaborative writing. At this juncture, students draft their essays in groups using the approved outline. Once the essay is completed, their group reviews the essay for content, structure and organization. Then, it is forwarded to another group for critiquing focusing on the same areas. After this, the group revises the paper based on the feedback of another group. It is expected that collaborative writing has provided enough scaffolding for students before they engage in individual writing.

During individual writing, students undergo almost the same procedure as they did during collaborative writing. Note that there is an interplay between drafting and revising during collaborative and individual writing. Just as in the collaborative writing, each student's text undergoes preparation, modeling and planning during the individual writing phase. Once the student has finished his/her outline, he/she starts writing his/her first draft. This first draft is then subjected to self-assessment, which focuses on the content, structure and organization. The student revises his/her work and forwards it to a peer for feedback. At this stage, the teacher may decide to pair the students. The peer reviewer reviews his/her classmate's work, using the designated rubric. Again, the focus during the peer review is on content, structure and organization. Prior to returning the paper to the student writer, the peer reviewer needs to subject the paper to plagiarism checking using available online tools, such as Plagtracker, Turnitin and Grammarly. Once done, he/she needs to discuss her comments with the student writer. The student writer then revises his/her work (i.e., second draft) based on the comment of his peer. The last phase of drafting and revision involves the teacher. The student writer forwards his/her work to the teacher for feedback. In the same fashion, the teacher focuses on the content, structure and organization of the paper using the designated rubric. After completing the review, he/she returns the paper, with his/her comments, to the student writer for final revision. The student writer revises his/her work based on the comments of the teacher. This is the final draft which will be subjected to editing.

While editing, the student checks his/her paper for grammatical and typographical accuracy. He/she may choose any or a combination of the following editing schemes: self-editing, online editing, or peer editing. When self-editing, the student edits his/her own work using his/her knowledge of English or an online editing tool such as Grammarly. He/she may also opt to ask a friend (preferably a proficient one) to edit his/her work. 
The final stage of writing is the publication of the student's work. Through this, the student would have a sense of authorship and readership. Preferably, students should publish their work on Facebook for a wider audience. However, they can also use other platforms such as Open Source Porffolio Initiative (OSPI), Mahara and Elgg.

\section{3 e-portfolio preparation}

To facilitate the preparation of the e-portfolio, an in-class session may be organized by the teacher. This session guides the students in step-by-step preparation of their e-portfolio. The teacher may provide a sample e-portfolio and demonstrate how it is used. The components of the e-portfolio could include the cover letter that introduces the content and highlights of the students' work, the course objectives, the entry essay that serves as a pretest, the major essays produced during the writing sessions, the exit essay that serves as a posttest and the reflective essay that presents the students' progress before and after the course. Note that portfolio assessment uses a delayed evaluation. Thus, students can still revise their work so long as they have not posted it yet on the class Facebook account for final grading.

\section{4 e-portfolio publication}

There are several available means of posting the e-portfolio on Facebook. The first way is through its Notes section. Although feasible, this section does not allow the incorporation of visuals, making it a static e-portfolio. Another option is to use PowerPoint (PPT) and convert it into a video. According to Apperson et al. (2006), PPT makes the presentation more organized and interesting.

To do this, open the PPT file that you want to share. In the File Tab, click Save $A s$. Then, write the filename of the PPT in the filename box and click the Windows Media Video from the Save As Type. On your Facebook account, click Add Photo/Video and select your .wmv file. Attach and post it on your Facebook account. The problem with this method is its lack of flexibility in controlling the transition from one slide to another and the clarity of texts.

Instead, I recommend that PPT via authorSTREAM be used for posting the e-portfolio because it allows the reader to easily control the transition from one slide to another. To do this, you may use the following steps: 
1. Go to the Home section of Facebook.

2. Click App Center.

3. Click Search for Apps.

4. Type authorSTREAM in the search tab.

5. Click Go to App.

6. Click My Presentation.

7. Click Upload My First Presentation.

8. Click Attach a PPT.

Afterwards, the students need to tag their posted e-portfolio to the class Facebook account for final grading. To reduce the anxiety of students on exposing their work to public readers, they may limit the privacy setting to people they consider a friendly audience (Barrot 2016). Once posted, students may be encouraged to post their appreciative comments on their classmates' work. This will further reduce the anxiety and apprehensions of students as regards posting their work. In case inappropriate comments are posted, the owner of the work may delete such comments. Since students' work will be graded only after publishing their e-portfolio, they will not receive their final grade until they do so.

\subsection{What makes Facebook a viable e-portfolio platform}

As reviewed, several studies have confirmed the viability of Facebook as a tool for teaching writing (e.g. Barrot 2016, Dizon 2016, Shepherd 2015, Shih 2011, Wichadee 2013). As reported by both students and teachers, a Facebook-based e-portfolio makes student writers more aware of their audience and the rhetorical context in which the essays are written. They also reported that they become more familiar with the publishing process and enhance their technical skills.

On top of a wider readership, real-time publication of work, flexibility, interactive features, accessibility, practicality and appeal of Facebook, the two other reasons Facebook publishing helps students improve their writing are social pressure and increased awareness of audience (Barrot 2016). In terms of social pressure, it functions as a double-edged sword. Negatively, it causes anxiety among students if they know that their work will be available online. This anxiety is rooted in the students' sense of privacy (Sánchez et al. 2014), self-idealization (i.e., one's view of himself/herself as having an ideal virtual identity) (Back et al. 2010) and peer exclusivity (i.e., one's willingness and openness to share information only with people whom he/she considers as acquaintances, friends, or relatives) (Shepherd 2015). However, this type of anxiety is of more of an enabling than a debilitating one, as manifested in their writing performance. In fact, some students reported that publishing their work online motivates them to do better and to be more reflective of what they would write.

Another factor that makes a Facebook-based e-portfolio contributory to students' writing performance is its ability to increase their awareness of their 
target audience. This effect is reinforced by the preparation stage undertaken by the students during the writing process. This awareness helps students adjust their content and language to their target audience.

\section{Conclusion}

I have provided an overview of portfolio assessment and how the influence of Facebook permeates the field of education. Based on a number of studies, it can be surmised that Facebook is and will be a viable tool for teaching and learning language skills. More particularly, I have synthesized the advantages and reasons for the positive influence of Facebook on developing students' writing performance. Finally, I have proposed means of implementing a Facebook-based e-portfolio in EFL/ESL writing classrooms.

Despite the benefits of using a Facebook-based e-portfolio, some challenges may be experienced by the students, teachers and institutions. First and foremost is the privacy issue. Although their output is limited to the reading of selected friends and classmates, some student writers may still feel that Facebook is an inappropriate venue for their academic work. This is because Facebook is essentially intended for personal and not for educational use. Second, there is also no assurance that the target readers will read the posted output, so there is no guarantee of having a wider readership for their work. Third, since this e-portfolio is web-based, the Internet connection may be a challenge in some educational contexts, more particularly in developing countries. These countries may have a very limited Internet connection, which makes it difficult or impossible to realize this type of portfolio. Others, although they have adequate Internet provision, may have very weak signals, which makes the posting problematic. Lastly, Facebook's terms and conditions may limit students' posting of texts, pictures and videos.

With advances in technology, the PPT format may not be that engaging anymore. Many students reported that they had difficulties in reading the e-portfolio via PPT. Hence, other options need to be explored to make the e-portfolio more engaging and interactive. One way is to use Microsoft Sway, which is a tool that allows users to create and share interactive reports and presentations via a web page. It suggests searches to find relevant images, videos and texts and instantly transforms content into an appealing design. The output in Sway can be easily shared via links, but a web page created via Microsoft Sway may still need to be posted or linked to students' and the class's Facebook account.

Given the exponential growth of technology in education, there is no other way but to move forward. We should be well-informed about all the apps we could use. And we should know what we want to do with them and how we can do it. Either we adapt or become obsolete. The choice is ours. 


\section{References}

Ajjan, Haya; Hartshorne, Richard (2008): Investigating faculty decisions to adopt Web 2.0 technologies: Theory and empirical tests. In: The Internet and Higher Education 11/2, 71-80.

Akbari, Elham; Pilot, Albert; Simons, P. Robert-Jan (2015): Autonomy, competence, and relatedness in foreign language learning through Facebook. In: Computers in Human Behavior 48, 126-134.

Apperson, Jennifer; Laws, Eric; Scepansky, James (2006): The impact of presentation graphics on students' experience in the classroom. In: Computers \& Education 47/1, 116-126.

Aydin, Selami (2012): A review of research on Facebook as an educational environment. In: Educational Technology Research and Development 60/6, 1093-1106.

Aydin, Selami (2014): FL writers' attitudes and perceptions toward F-Portfolio use. In: TechTrends 8/2, 59-77.

Back, Mitja; Stopfer, Juliane; Vazire, Simine; Gaddis, Sam; Schmukle, Stefan; Egloff, Boris; Gosling, Samuel (2010): Facebook profiles reflect actual personality, not self-idealization. In: Psychological Science 21/3, 372-374.

Barrot, Jessie (2014): A macro perspective on key issues in English as second language (ESL) pedagogy in the postmethod era: Confronting challenges through sociocognitive-transformative approach. In: The Asia-Pacific Education Researcher 23/3, 435-449.

Barrot, Jessie (2015a): A sociocognitive-transformative approach to teaching writing: Theory and praxis. In: Indonesian Journal of Applied Linguistics 4/2, 111-120.

Barrot, Jessie (2015b): A sociocognitive-transformative instructional materials design model for second language (L2) pedagogy in the Asia Pacific: Development and validation. In: The Asia-Pacific Education Researcher 24/2, 283-297.

Barrot, Jessie (2016): Using Facebook-based e-portfolio in ESL writing classrooms: impact and challenges. In: Language, Culture and Curriculum 29/3, 286-301.

Barrot, Jessie (2018): Using the sociocognitive-transformative approach in writing classrooms: Effects on L2 learners' writing performance. In: Reading \& Writing Quarterly 34/2, 187-201.

Baturay, Meltem Huri; Daloğlu, Ayşegül (2010): E-portfolio assessment in an online English language course. In: Computer Assisted Language Learning 23/5, 413-428.

Blankenship, Mark (2011): How social media can and should impact higher education. In: Education Digest: Essential Readings Condensed for Quick Review 76/7, 39-42. 
Bowers-Campbell, Joy (2008): Cyber "pokes": Motivational antidote for developmental college readers. In: Journal of College Reading and Learning 39/1, 74-87.

Brown, James; Hudson, Thom (1998): The alternatives in language assessment. In: TESOL Quarterly 32/4, 653-675.

Byon, Andrew (2007): The use of culture portfolio project in a Korean culture classroom: Evaluating stereotypes and enhancing cross-cultural awareness. In: Language, Culture and Curriculum 20/1, 1-19.

Camus, Miguel (2018): PH is world leader in social media usage. In: Philippine Daily Inquirer. http:/ / business.inquirer.net/246015/ph-world-leader-social-mediausage [26.06.2019].

Challis, Diana (2005): Towards the mature ePortfolio: Some implications for higher education. In: Canadian Journal of Learning and Technology 31/3, 1-13.

Cheng, Gary (2009): Implementation challenges of the English language e-portfolio system from various stakeholder perspective. In: Journal of Educational Technology Systems 37/1, 97-118.

Chun, Dorothy; Plass, Jan (1997): Research on text comprehension in multimedia environments. In: Language Learning \& Technology 1/1, 60-81.

Chye, Stefanie; Liau, Albert; Liu, Woon Chia (2013): Student teachers' motivation and perceptions of e-portfolio in the context of problem-based learning. In: The Asia-Pacific Education Researcher 22/4, 367-375.

Dizon, Gilbert (2016): A comparative study of Facebook vs. paper-and-pencil writing to improve L2 writing skills. In: Computer Assisted Language Learning 29/8, 1249-1258.

Ellison, Nicole; Steinfield, Charles; Lampe, Cliff (2007): The benefits of Facebook "friends": Social capital and college students' use of online social network sites. In: Journal of Computer-Mediated Communication 12/4, 1143-1168.

Facebook (2018): Stats. http://newsroom.fb.com/company-info/ [26.06.2019].

Greenhow, Christine (2009): Tapping the wealth of social networks for professional development. In: Learning and Leading with Technology 36/8, 10-11.

Greenhow, Christine; Lewin, Cathy (2016). Social media and education: Reconceptualizing the boundaries of formal and informal learning. In: Learning, Media and Technology 41/1, 6-30.

Hamp-Lyons, Liz; Condon, William (2000). Assessing the Portfolio: Principles for Practice, Theory, and Research. Cresskill, New Jersey: Hampton Press.

Hew, Khe Foon (2011): Students' and teachers' use of Facebook. In: Computers in Human Behavior 27/2, 662-676.

Hsu, Shihkuan (2011): Who assigns the most ICT activities? Examining the relationship between teacher and student usage. In: Computers \& Education 56/3, 847-855. 
Jong, Bin-Shyan; Lai, Chien-Hung; Hsia, Yeh-I; Lin, Tsong-Wuu; Liao, Yu-Syuan (2014): An exploration of the potential educational value of Facebook. In: Computers in Human Behavior 32, 201-211.

Kabilan, Muhammad Kamarul; Ahmad, Norlida; Abidin, Mohamad (2010): Facebook: An online environment for learning of English in institutions of higher education? In: The Internet and Higher Education 13/4, 179-187.

Kabilan, Muhammad Kamarul; Khan, Mahbub Ahsan (2012): Assessing preservice English language teachers' learning using e-portfolios: Benefits, challenges and competencies gained. In: Computers \& Education 58/4, 1007-1020.

Kern, Richard; Warschauer, Mark (2000): Theory and practice of network-based language teaching. In: Warschauer, Mark; Kern, Richard (eds.): Network-based Language Teaching. Cambridge: Cambridge University Press, 1-19.

Kessler, Greg; Hubbard, Philip (2017): Language teacher education and technology. In: Chapelle, Carol; Sauro, Shannon (eds.): The Handbook of Technology and Second Language Teaching and Learning. New Jersey: Wiley \& Sons, 278-292.

Khan, Mohamad; Hasan, Mahbub; Clement, Che Kum (2012): Barriers to the introduction of ICT into education in developing countries: The example of Bangladesh. In: International Journal of Instruction 5/2, 61-80.

Lam, Ricky (2014): Promoting self-regulated learning through portfolio assessment: testimony and recommendations. In: Assessment \& Evaluation in Higher Education 39/6, 699-714.

Lam, Ricky (2017): Taking stock of portfolio assessment scholarship: From research to practice. In: Assessing Writing 31, 84-97.

Lampe, Cliff; Ellison, Nicole; Steinfield, Charles (2008): Changes in use and perception of Facebook. In: Proceedings of the 2008 ACM Conference on Computer Supported Cooperative Work. New York: ACM, 721-730. http:/ /www.personal. umich.edu/ enicole/LampeEllisonSteinfield2008.pdf [05.04.2019].

Lee, Icy (2017): Portfolios in classroom L2 writing assessment. In: Lee, Icy (ed.): Classroom Writing Assessment and Feedback in L2 School Contexts. Singapore: Springer, 105-122.

Lomicka, Lara; Lord, Gillian (2016): Social networking and language learning. In: Farr, Fiona; Murray, Liam (eds.): The Routledge Handbook of Language Learning and Technology. Basingstoke: Taylor \& Francis, 255-268.

Lorenzo, George; Ittelson, John (2005): An overview of e-portfolios. In: Educause Learning Initiative 1, 1-27.

Madge, Clare; Meek, Julia; Wellens, Jane; Hooley, Tristram (2009): Facebook, social integration and informal learning at university: 'It is more for 127auges127ze127g and talking to friends about work than for actually doing work'. In: Learning, Media and Technology 34/2, 141-155. 
Makri, Katerina; Schlegelmilch, Bodo (2017): Time orientation and engagement with social networking sites: A cross-cultural study in Austria, China and Uruguay. In: Journal of Business Research 80, 155-163.

Malcolm, Janice; Hodkinson, Phil; Colley, Helen (2003): The interrelationships between informal and formal learning. In: Journal of Workplace Learning 15/(7/8), 313-318.

Manca, Stefania; Ranieri, Maria (2013): Is it a tool suitable for learning? A critical review of the literature on Facebook as a technology-enhanced learning environment. In: Journal of Computer Assisted Learning 29/6, 487-504.

Manca, Stefania; Ranieri, Maria (2016): Facebook and the others. Potentials and obstacles of social media for teaching in higher education. In: Computers \& Education 95, 216-230.

Mazman, Sacide; Usluel, Yasemin (2010): Modeling educational usage of Facebook. In: Computers \& Education 55/2, 444-453.

Meyer, Elizabeth; Abrami, Philip; Wade, Anne; Aslan, Ofra; Deault, Louise (2010): Improving literacy and metacognition with electronic portfolios: Teaching and learning with ePEARL. In: Computers \& Education 55/1, 84-91.

Mills, Nicole (2011): Situated learning through social networking communities: The development of joint enterprise, mutual engagement, and a shared repertoire. In: CALICO Journal 28/2, 345-368.

Morris, Joyce (2003): Digital portfolios reflect how we learn. In: Crawford, Caroline; Willis, Dee Anna; Carlsen, Roger; Gibson, Ian; McFerrin, Karen; Price, Jerry; Weber, Roberta (eds.): Proceedings of Society for Information Technology and Teacher Education International Conference 2003. Chesapeake, VA: AACE, 122-127.

Nadkarni, Ashwini; Hofmann, Stefan (2012): Why do people use Facebook? In: Personality and Individual Differences 52/3, 243-249.

Ndebele, Hloniphani (2017): Social software as a tool of promoting indigenous African languages in Higher Education. In: International Journal of Multilingualism 15/1, 92-112.

O’Bannon, Blanche; Beard, Jeffrey; Britt, Virginia (2013): Using a Facebook group as an educational tool: Effects on student achievement. In: Computers in the Schools 30/3, 229-247.

Özdemir, Emrah (2017): Promoting EFL learners' intercultural communication effectiveness: a focus on Facebook. In: Computer Assisted Language Learning $30 / 6,510-528$.

Prescott, Julie; Wilson, Sarah; Becket, Gordon (2013): Facebook use in the learning environment: do students want this? In: Learning, Media and Technology 38/3, 345-350. 
Prescott, Julie (2014): Teaching style and attitudes towards Facebook as an educational tool. In: Active Learning in Higher Education 15/2, 117-128.

Ramirez, Alex; Hine, Michael; Ji, Shaobo; Ulbrich, Frank; Riordan, Rob (2009): Learning to succeed in a flat world: Information and communication technologies for a new generation of business students. In: Learning Inquiry 3/3, 157-175.

Robelia, Beth; Greenhow, Christine; Burton, Lisa (2011): Environmental learning in online social networks: Adopting environmentally responsible behaviors. In: Environmental Education Research 17/4, 553-575.

Roblyer, Margaret; McDaniel, Michelle; Webb, Marsena; Herman, James; Witty, James (2010): Findings on Facebook in higher education: A comparison of college faculty and student uses and perceptions of social networking sites. In: The Internet and Higher Education 13/3, 134-140.

Russell, James; Butcher, Cheryl (1999): Using portfolios in educational technology courses. In: Journal of Technology and Teacher Education 7/4, 279-289.

Sánchez, Rocio; Cortijo, Virginia; Javed, Uzma (2014): Students' perceptions of Facebook for academic purposes. In: Computers \& Education 70, 138-149.

Sarapin, Susan; Morris, Pamela (2015): Faculty and Facebook friending: Instructorstudent online social communication from the professor's perspective. In: The Internet and Higher Education 27, 14-23.

Schroeder, Jacob; Greenbowe, Thomas (2009): The chemistry of Facebook: Using social networking to create an online community for the organic chemistry laboratory. In: Innovate: Journal of Online Education 5/4, 1-11.

Schwartz, Harriet (2009): Facebook: The new classroom commons? In: Chronicle of Higher Education 56/6, B12-B13.

Selwyn, Neil (2009): Faceworking: exploring students' education-related use of Facebook. In: Learning, Media and Technology 34/2, 157-174.

Shepherd, Ryan (2015): FB in FYC: Facebook use among first-year composition students. In: Computers and Composition 35, 86-107.

Shih, Ru-Chu (2011): Can Web 2.0 technology assist college students in learning English writing? Integrating Facebook and peer assessment with blended learning. In: Australasian Journal of Educational Technology 27/5, 829-845.

Shih, Ru-Chu (2013): Effect of using Facebook to assist English for Business Communication course instruction. In: Turkish Online Journal of Educational Technology-TOJET 12/1, 52-59.

Shin, Ryan (2010): Taking digital creativity to the art classroom: Mystery box swap. In: Art Education 63/2, 38-42.

Siegle, Del (2011): Cyberbullying and sexting: Technology abuses of $21^{\text {st }}$ century. In: Gifted Child Today 34/2, 14-16. 


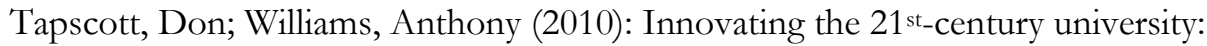
It's time! In: Educause Review 45/1, 16-29.

Traore, Moussa; Kyei-Blankson, Lydia (2011): Using literature and multiple technologies in ESL instruction. In: Journal of Language Teaching and Research 2/3, 561-568.

Tsai, Roland; Jenks, Michael (2009): Teacher-guided interactive multimedia for teaching English in an EFL context. In: Journal of Educational Multimedia and Hypermedia 18/1, 91-111.

Voogt, Joke; Knezek, Gerald; Cox, Margaret; Knezek, Don; ten Brummelhuis, Alfons (2013): Under which conditions does ICT have a positive effect on teaching and learning? A call to action. In: Journal of computer assisted learning 29/1, 4-14.

Wang, Yuewu (2004): English magazines, motivation, and improved EFL writing skill. In: English Teaching Forum 42/1, 24-29.

Waters, John (2009): E-portfolios come of age. In: T.H.E. Journal 36/10, 23-29.

Weigle, Sara (2007): Teaching writing teachers about assessment. In: Journal of Second Language Writing 16/3, 194-209.

Werquin, Patrick (2010): Recognising Non-formal and Informal Learning: Outcomes, Policies and Practices. Paris: OECD Publishing.

West, Anne; Lewis, Jane; Currie, Peter (2009): Students' Facebook “friends": Public and private spheres. In: Journal of Youth Studies 12/6, 615-627.

Wichadee, Saovapa (2013): Peer feedback on Facebook: The use of social networking websites to develop writing ability of undergraduate students. In: Turkish Online Journal of Distance Education 14/4, 260-270.

Yang, Yuqin; Wang, Qiyun; Woo, Huay Lit; Quek, Choon Lang (2011): Using Facebook for teaching and learning: A review of the literature. In: International Journal of Continuing Engineering Education and Life-Long Learning 21/1, 72-86.

Yen, Yen-Chen; Hou, Huei-Tse; Chang, Kuo-En (2015): Applying role-playing strategy to enhance learners' writing and speaking skills in EFL courses using Facebook and Skype as learning tools: A case study in Taiwan. In: Computer Assisted Language Learning 28/5, 383-406.

Zusho, Akane; Edwards, Kelcey (2011): Self-regulation of achievement goals in the college classroom. In: Bembenutty, Hefer (ed.): Self-regulated Learning: New Directions for Teaching and Learning, no. 126. San Francisco: Jossey-Bass, 21-31. 